\title{
INFRAESTRUTURA VERDE PARA AS MUDANÇAS CLIMÁTICAS NO C40
}

\author{
Maria de Assunção Ribeiro Franco* \\ *É Professora Titular do Departamento de Projeto da FAUUSP. Coordena o Laboratório LABVERDE, e é \\ editora da REVISTA LABVERDE, na mesma instituição. Atualmente presta consultoria em Planejamento e \\ Desenho Ambiental e Infraestrutura Verde. \\ mariafranco@usp.br \\ Vera Cristina Osse ${ }^{* *}$ \\ **É Professora Doutora em Estruturas Ambientais Urbanas pela FAUUSP e leciona atualmente na FAU- \\ Mackenzie. Trabalha como autônoma em projetos e consultoria na área de Arquitetura e Desenho Ambiental. \\ vosse100@gmail.com \\ VOLKER MINKs*** \\ ${ }^{* * * E}$ engenheiro agrônomo e urbanista pela Universidade de Humboldt de Berlim. Tem trabalhado em diver- \\ sos projetos de design verde, com aplicação de novas tecnologias em paredes e tetos verdes na Alema- \\ nha, Cuba, Estados Unidos e Brasil. \\ volker.minks@gmx.de
}

\section{RESUMO}

Atualmente, em todo o mundo, as cidades se preparam para as mudanças climáticas. $\mathrm{O}$ presente artigo trata da experiência do encontro C40, realizado em São Paulo em meados de 2011 e promovido pela Prefeitura, que reuniu dezenas de cidades do mundo inteiro para discutir estratégias para o enfrentamento do problema com várias abordagens como: o uso de energias renováveis, gestão do lixo, mobilidade urbana e arborização urbana entre outras. Os autores deste artigo foram convidados a participar do evento como consultores e relatores da Sessão 3 - Arborização e Floresta Urbana - trabalho que resultou num texto sobre o assunto, o qual gerou o presente artigo.

Na sessão Arborização e Floresta Urbana foram apresentadas iniciativas de incremento de áreas verdes adotadas por cidades de quatro países diferentes - Rússia, Chile, Nigéria e Etiópia - os quais se fizeram presentes, respectivamente, por meio de representantes das cidades de Moscou, Santiago, Lagos e Adis Abeba; todos reunidos com um mesmo objetivo principal: a adaptação das cidades às mudanças climáticas. No encontro, ficou patente, que o plantio de árvores está entre as principais ações de adaptação das cidades, com a finalidade de melhorar a infraestrutura verde e enfrentar o problema das "ilhas de calor" e do "aquecimento global". O plantio dá-se principalmente 
nos parques, praças, nos espaços verdes das vias e na criação e recuperação de florestas. Além dessas, outras treze cidades têm planos semelhantes, referentes à criação ou expansão de cinturões e áreas verdes. Tendo como exemplo as medidas adotadas por essas quatro cidades do C40, e após uma discussão e reflexão pós-encontro, esta equipe faz, no final deste relato, uma conclusão e algumas recomendações, visando a consolidação de uma infraestrutura verde para a cidade de São Paulo, para promover sua resiliência urbana às mudanças climáticas.

Palavras-chave: infraestrutura verde; mudanças climáticas; arborização urbana; floresta urbana; resiliência urbana.

\title{
GREEN INFRASTRUCTURE FOR CLIMATE CHANGE IN THE C40
}

\begin{abstract}
Currently, worldwide, cities are preparing themselves for climate changes. This article deals with the experience of the meeting C40, held in São Paulo by mid-2011 and promoted by the City Authorities. The meeting brought together dozens of cities around the world to discuss strategies to face the problem with several approaches such as the use of renewable energy, waste management, urban mobility and urban afforestation among others. The authors of this article have been invited to attend that event as consultants and reporters of Session 3 - Tree Planting and Urban Forest. This work resulted in a text on the subject, which led to this article. In the session and Urban Forest and Tree Planting it was proposed initiatives to increase the green areas adopted by cities in four different countries - Russia, Chile, Nigeria and Ethiopia - which were attended by representatives of the cities Moscow, Santiago, Lagos and Addis Ababa, all together with the same main target: adapting cities to climate changes. At that meeting, it became evident that planting trees is among the main adaptation actions at the cities, with the aim to improve the green infrastructure and face the problem of "urban heat islands" and "global warming". Planting takes place mainly in parks, squares, green areas of pathways and with creation and restoration of forests. Besides these, thirteen other cities have similar plans concerning the creation or expansion of green belts and areas. Having as an example the measures adopted by these four cities at C40 and after discussion and reflection after-meeting, this team makes, at the end of this report,
\end{abstract}


a conclusion and some recommendations, aiming consolidating a green infrastructure for the city of São Paulo to promote its urban resilience to climate change.

Keywords: green infrastructure; climate changes, urban afforestation, urban forest, urban resilience.

\section{ARBORIZAÇÃO E FLORESTA URBANA NO C40}

Hoje se reconhece que as mudanças climáticas representam o maior desafio para a humanidade do século XXI, tanto no âmbito econômico quanto no ecológico e social. Na Sessão 3 do encontro C 40 - Arborização e Floresta Urbana - tornou-se evidente a prioridade da arborização e recriação de mais áreas verdes no processo de urbanização nas megacidades.

Representantes do Chile, da Rússia, da Nigéria e da Etiópia apresentaram iniciativas relevantes de seus países, onde vêm adotando medidas produtivas, como oportunidades de financiamento, planejamento e parceria, bem como a importância da administração na manutenção e preservação das áreas verdes. Os representantes apresentaram e discutiram os benefícios do plantio de árvores e dos programas de arborização urbana, assim como as dificuldades para a elaboração e implementação do projeto com os associados. $O$ plantio de árvores está entre as principais ações de adaptação das grandes cidades, com a finalidade de melhorar o desempenho da infraestrutura verde existente nas mesmas.

A sessão foi moderada pelo Sr. Almaz Mekonnen, Diretor de Relações Públicas e Internacionais de Adis Abeba. Vinte e um dos 40 membros, do Large Cities Climate Summit, implementaram iniciativas de arborização e programas de Florestas Urbanas como iniciativas de adaptação climática das cidades e investem, particularmente, em parques, espaços verdes, vias urbanas, e florestas. Treze cidades têm planos para expandir seus programas atuais de plantio de árvores.

Programas urbanos florestais têm importantes benefícios, como o de reduzir a vulnerabilidade ao estresse climático. Isso significa influenciar o microclima no interior das cidades, provocando a redução do efeito estufa, a melhoria da condição de moradia das nossas comunidades e do habitat para a vida selvagem urbana, assim como da qualidade do ar. Programas de arborização urbana tomam muitas formas e dependem de todos os tipos de parceiros para a sua implementação e manutenção contínua. 


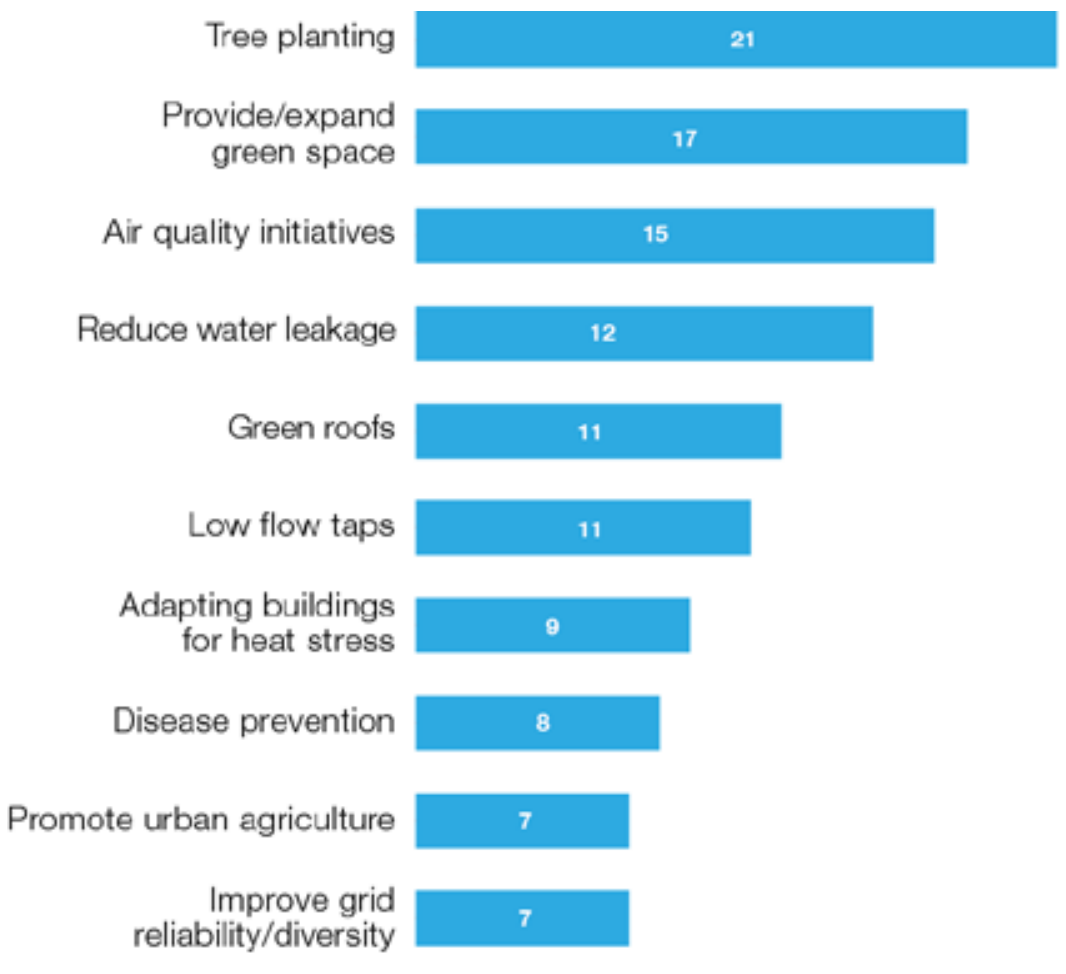

$0 \quad$ Number of Cities

25

Figura 01 - Medidas de infraestrutura verde adotadas pelas cidades participantes do encontro.

Fonte: C40 Cities Baseline Report -,Tree Planting and Urban Forestry ${ }^{1}$

\section{CIDADES MAIS VERDES}

\section{Moscou}

Moscou é a capital da Federação Russa, que tem cerca de $10.3^{2}$ milhões de habitantes na cidade; trata-se da maior aglomeração européia e uma das sete maiores do mundo. É o centro político, econômico e cultural do país. Moscou ocupa $1081 \mathrm{~km}^{2}$, dos quais $323,3 \mathrm{~km}^{2}$ são áreas verdes, ou cerca de $30 \%$ da área total da cidade, a qual conta com: 120 parques com 2,4 mil ha; 272 vias arborizadas com cerca de 1,3 mil ha; 392 praças, ocupando 700 ha; e 236 reservas naturais (áreas protegidas) de 17.000 ha. $^{3}$

\footnotetext{
${ }^{1}$ Rishi Desai - Assessor da Presidência do C40, Relatório Base de Cidades C40 - Arborização Urbana e Floresta Urbana, Junho de 2011.

2 www.c40cities.org/cities, 01/06/ 2011

${ }^{3}$ Apresentação do C40 Large Cities Climate Summit, Apresentação da Sessão 3 - Arborização Urbana e Floresta Urbana pelo Sr. Anton Kulbachevskiy, diretor do Departamento de Recursos Naturais e Proteção Ambiental de Moscou, Sao Paulo, Junho 2011
} 
Moscou é mais setentrional de todas as cidades metropolitanas. Esta posição geográfica impõe condições especiais de clima como: estação curta de crescimento das plantas, numerosos ciclos de congelamento e derretimento do solo, uso de agentes de degelo no final da primavera, e neve e granizo, que pesam nas árvores, fazendo-as cair. Para resolver os problemas de plantio em Moscou, não só o cuidado de especialistas em áreas verdes, ou o trabalho sobre a sua expansão e restauração, são suficientes, mas também o da seleção de espécies adequadas àquela situação, incluindo árvores, arbustos e flores.

Quase 70 milhões de toneladas de $\mathrm{CO}_{2}$ são lançados anualmente na atmosfera de Moscou. As estações de energia elétrica contribuem com quase a metade desse montante, e os meios de transporte até um terço desse número, que se acumula permanentemente. Tendo em conta que as áreas verdes da cidade têm o território de mais de $300 \mathrm{Km}^{2}$, deve-se esperar que a quantidade de dióxido de carbono absorvido pela vegetação não exceda 10.000 toneladas. Durante a temporada de verão em Moscou, as mudanças climáticas são bastante nítidas. A intensidade de "ondas de calor", o aumento de períodos de seca, a probabilidade de aparecimento de poluição causados pelos incêndios florestais na região é bastante elevado também. Por exemplo, os cidadãos de Moscou, no verão de 2010 , sofreram com temperaturas muito altas, de mais de $30^{\circ} \mathrm{C}$ durante 33 dias, sendo que a temperatura média do verão é de cerca de $23^{\circ} \mathrm{C}$. Nessas condições climáticas a importância de áreas verdes é difícil de não ser superestimada, pois vão servir como abrigos para os cidadãos. Além disso, o tráfego pesado, com o tempo seco e quente, lança na atmosfera substâncias tóxicas e venenosas provocando o fenômeno chamado "Los Angeles smog", bastante comum em Moscou.

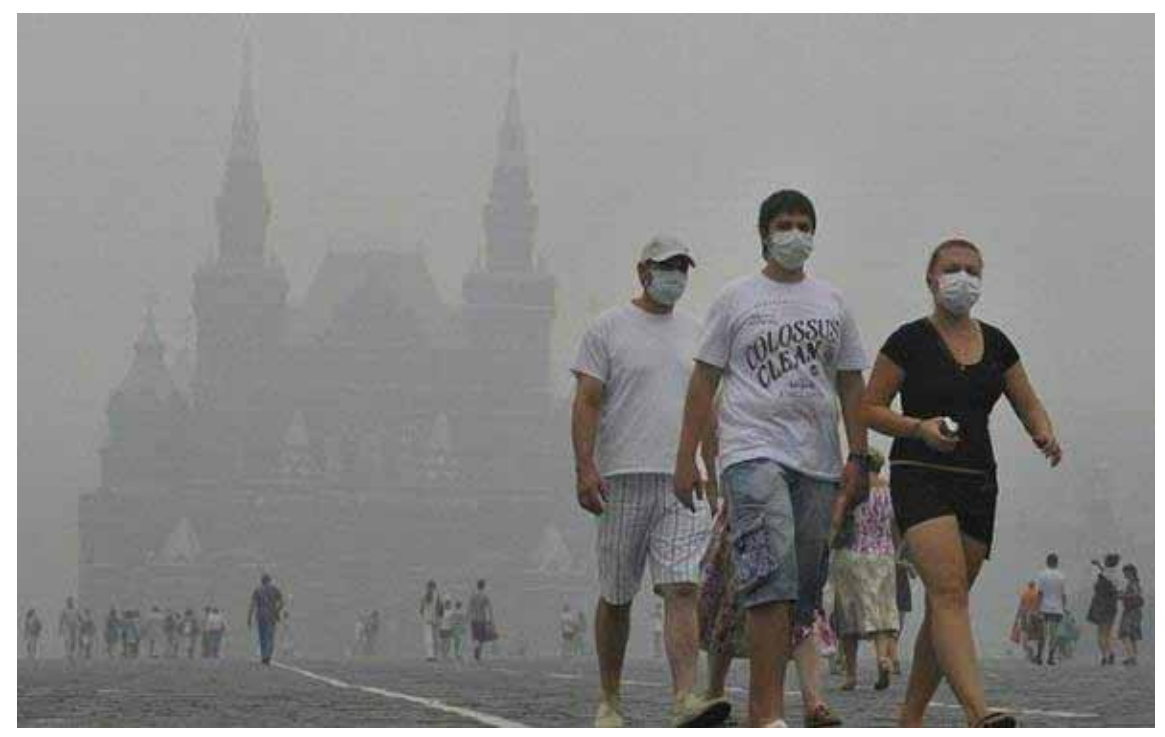

Figura 02 - Pessoas caminhando na Praça Vermelha, em meio ao "Los Angeles smog", fenômeno comum na cidade de Moscou provocado pela emissão de poluentes tóxicos do tráfego pesado, em tempo quente e seco.

Fonte: Apresentação do C40 Large Cities Climate Summit São Paulo: The Case of Moscou, May,June,1/ 2011 
As atividades no plantio compensatório de vegetação em Moscou, para o ano de 2011, foram adotadas com o propósito de preservação e desenvolvimento de áreas verdes, e incluem não só o trabalho na plantação de florestas urbanas, mas também todo o conjunto de melhorias e obras de manutenção. O papel dos espaços verdes pode ser considerado significativo, tendo em vista a compensação para as emissões; mas a cidade está se esforçando para estabelecer mais novas áreas verdes e o desenvolvimento das já existentes. O Programa de Proteção Ambiental de Moscou (2012-2016) mostrou que está trabalhando nesse sentido, especialmente no plantio de florestas urbanas como meta prioritária de governo.

\section{Lagos}

Lagos é a maior cidade da Nigéria, e foi sua capital até $1991 .{ }^{4}$ Com 9,7 milhões de habitantes ${ }^{5}$ é a mais populosa da África, e o centro financeiro, bancário, econômico e cultural do país, além de ser o pólo mais importante de transportes. Apresenta uma taxa de crescimento notável da população, de $6 \%$ ao ano e prevê-se que em 2015, abrigará cerca de 25 milhões de pessoas. Em Lagos situam-se mais de $10.000 \mathrm{em}$ presas industriais e comerciais e uma considerável concentração de veículos. A cidade fica na costa do Golfo da Guiné, numa média de cinco metros acima do nível do mar, e se estende bordejando uma lagoa, onde se pratica aquicultura extensiva, por entre ilhas e manguezais, cercada por coqueiros e floresta tropical.

A região metropolitana de Lagos tem uma área de $14.144 \mathrm{~km}^{2}$ e se estende por todo o estado de Lagos, e grande parte do estado de Ogun e vem lutando, como muitas outras grandes cidades, contra estradas desastrosas, a superlotação e as péssimas condições de tráfego. Esta situação foi reconhecida pelo estado e pela população, que iniciou um processo de discussão.

Em 1960, ano da independência da Nigéria, e por alguns anos depois, Lagos - primeiro como território da capital federal e, posteriormente, como Lagos Estado - foi uma cidade de jardins, hipódromos, parques, campos de flores e fauna. Na verdade, Lagos ficou famosa por sua participação na série de competições de flores locais e

\footnotetext{
${ }^{4}$ Desde 1991, Abuja é a nova capital da Nigéria

${ }^{5}$ www.c40cities.org/cities, 01/06/ 2011
} 
nacionais. Tudo isso foi perdido com o advento do "boom" do petróleo, na década de 1970, que testemunhou um frenesi de construção, dando atenção insuficiente para a vegetação.

O desenvolvimento urbano em Lagos está intimamente ligado à história, e o "Programa Lagos Verde", pretende causar uma reviravolta. Lagos investiu em tecnologia, propiciando o plantio de árvores de maior porte, que vieram contribuir de forma mais eficaz na mudança dos efeitos climáticos, adotando novas estratégias de sustentabilidade com a implementação de áreas verdes, como vias arborizadas, jardins, parques e florestas, que contribuirão no futuro para amenizar o microclima.
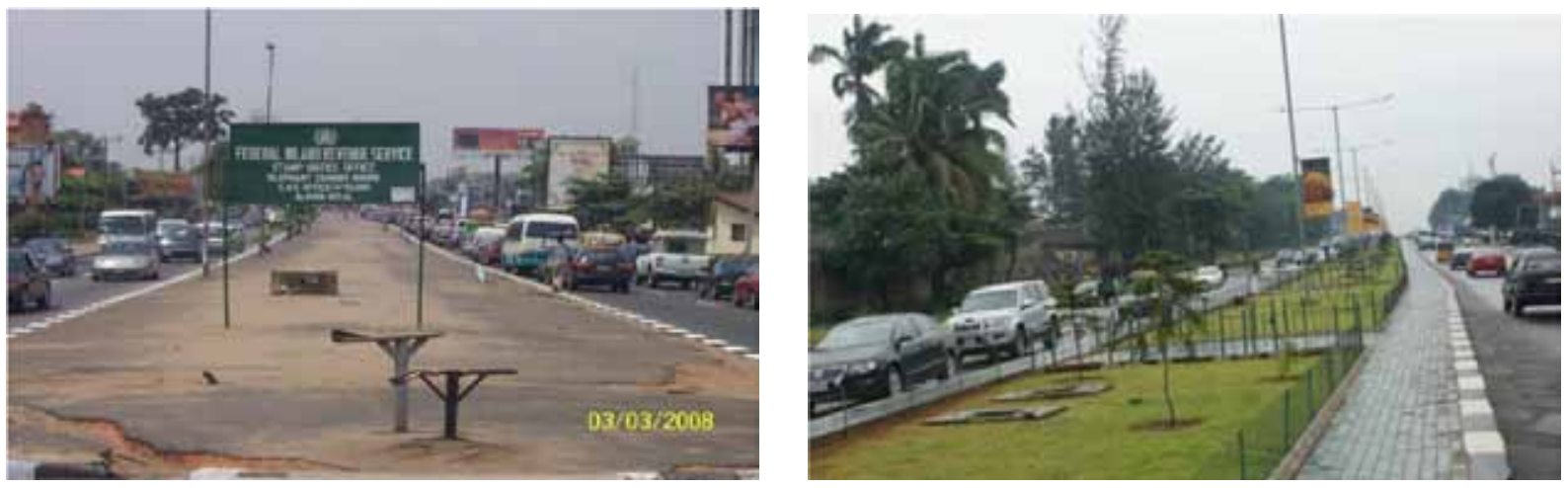

Figura 03 - O antes e depois de uma ação de arborização urbana em uma avenida na cidade de Lagos, Nigéria. Fonte: Apresentação do C40 Large Cities Climate Summit São Paulo: The Case of Lagos, 01/06/ 2011
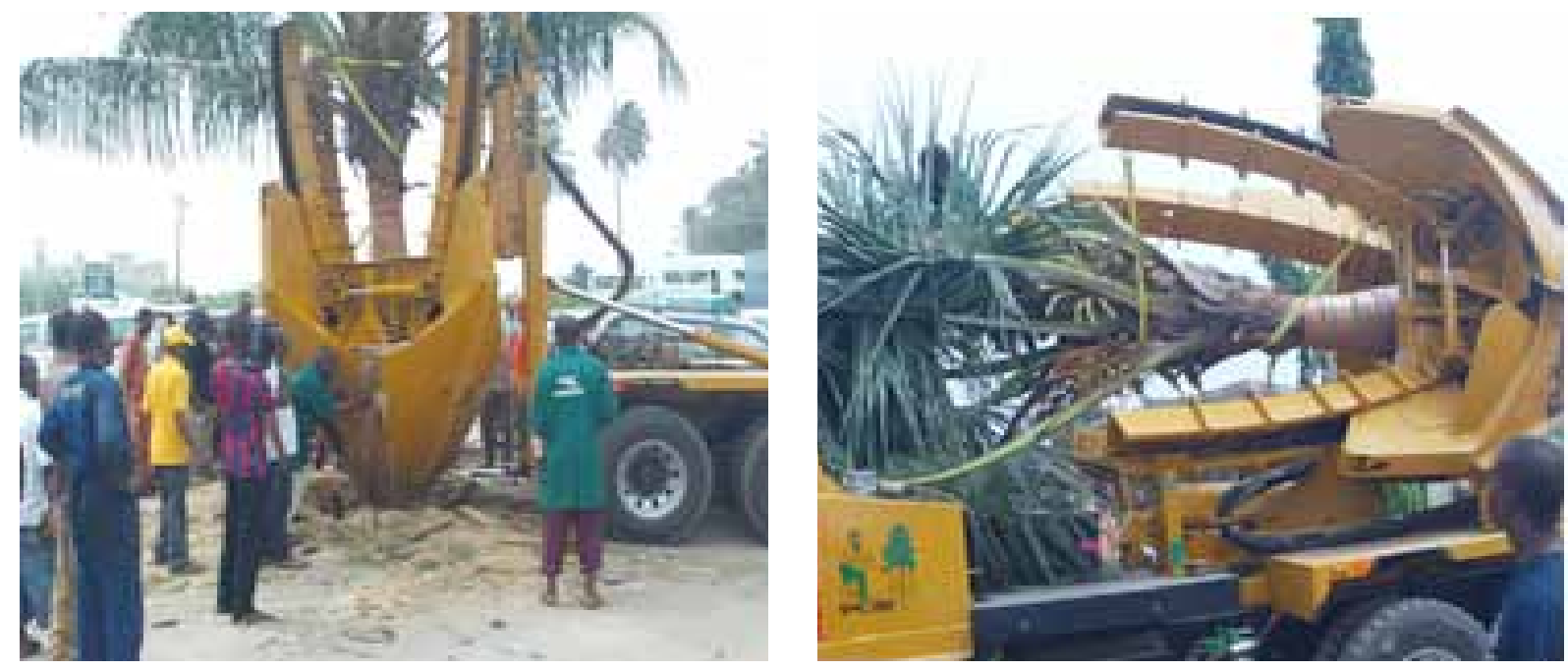

Figura 04 - Adoção de máquinas e de novas tecnologias adotadas pelo governo para o programa de plantio de milhares de árvores na cidade de Lagos, Nigéria.

Fonte: Apresentação do C40 Large Cities Climate Summit São Paulo: The Case of Lagos, 01/06/ 2011 


\section{Santiago do Chile}

Santiago do Chile estende sua região Metropolitana numa área de 15.403,2 km², equivalente a $2 \%$ da superfície do país. A população regional é de 6 milhões, ou $40 \%$ da população total, com uma densidade de 393hab/ $\mathrm{km}^{2}$. Essa região vem sofrendo uma serie de alterações climáticas, principalmente quanto à aridez e o aumento de temperatura (1 a 2 graus) em todas as estações. Situa-se geograficamente numa depressão junto à cordilheira dos Andes, como se observa em foto abaixo (fig.05).
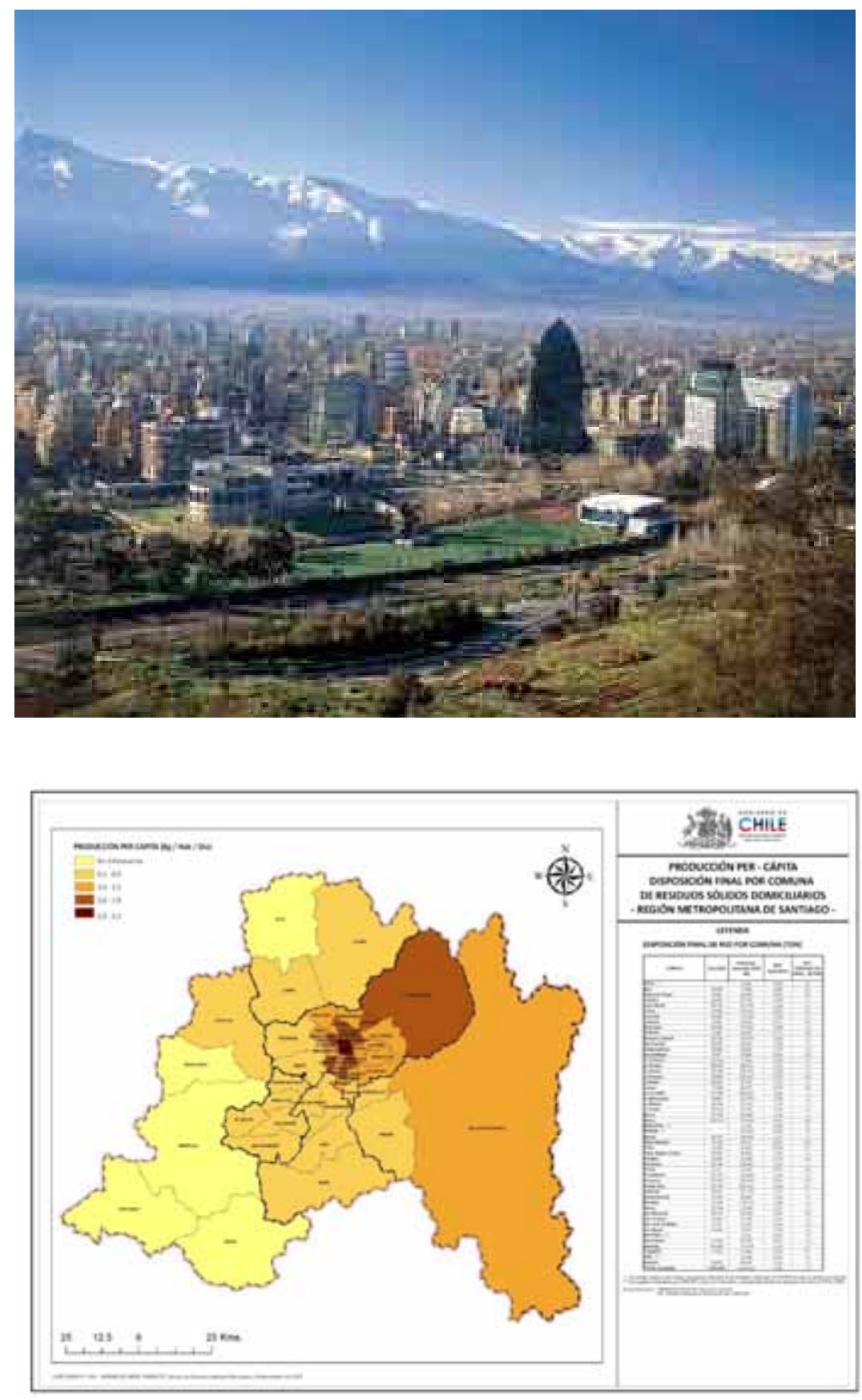

Figura 05 - A Cidade de Santiago do Chile, tendo ao fundo a cordilheira dos Andes. Fonte: Apresentação do C40 large Cities Climate Summit São Paulo Brazil:Cambio Climático -Região Metropolitana Santiago do Chile May, 01/06/ 2011

Figura 06 - Região Metropolitana de Santiago do Chile.

Fonte: Apresentação do C40 large Cities Climate Summit São Paulo Brazil:Cambio Climático Região Metropolitana Santiago do Chile May, 01/06/ 2011 
Com o objetivo principal de analisar os impactos da mudança de clima, a prefeitura de Santiago, entre 2009-2012, firmou um convenio de colaboração e desenvolvimento do projeto "Clima Adaptación Santiago", pois existe a perspectiva de que a região sofrerá uma diminuição nas precipitações totais anuais da ordem de $20 \%$. Portanto, um manejo adequado das áreas com a vegetação urbana, pode vir a minimizar os efeitos trazidos pelas mudanças climáticas, e contribuir para um aumento do grau higrométrico, propiciando mais umidade e, conseqüentemente, uma melhor qualidade de vida para a população. O governo criou também, uma Política de Áreas Verdes com um programa denominado "Presidencial", que incentivou o plantio de uma árvore para cada chileno. A meta em 2010 era de 6 milhões de novas árvores.

É provável que a Região Metropolitana no futuro fique mais quente e árida, com as precipitações concentradas no mês de inverno e altas temperaturas no verão, todavia ainda há muitas incertezas, pois os modelos climáticos ainda podem sofrer inúmeras alterações.

\section{Addis Abeba}

Addis Abeba,capital federal da Etiópia, conta com 3 milhões de habitantes, distribuídos numa área de $540 \mathrm{~km}^{2}$. Esta área, que teve uma densa cobertura vegetal natural, hoje se vê ocupada por reflorestamentos de eucaliptos e apresenta um índice pluviométrico relativamente baixo de $1200 \mathrm{~mm}$ anuais, em decorrência de seu habitat ter sido seriamente devastado por problemas de ocupação humana.

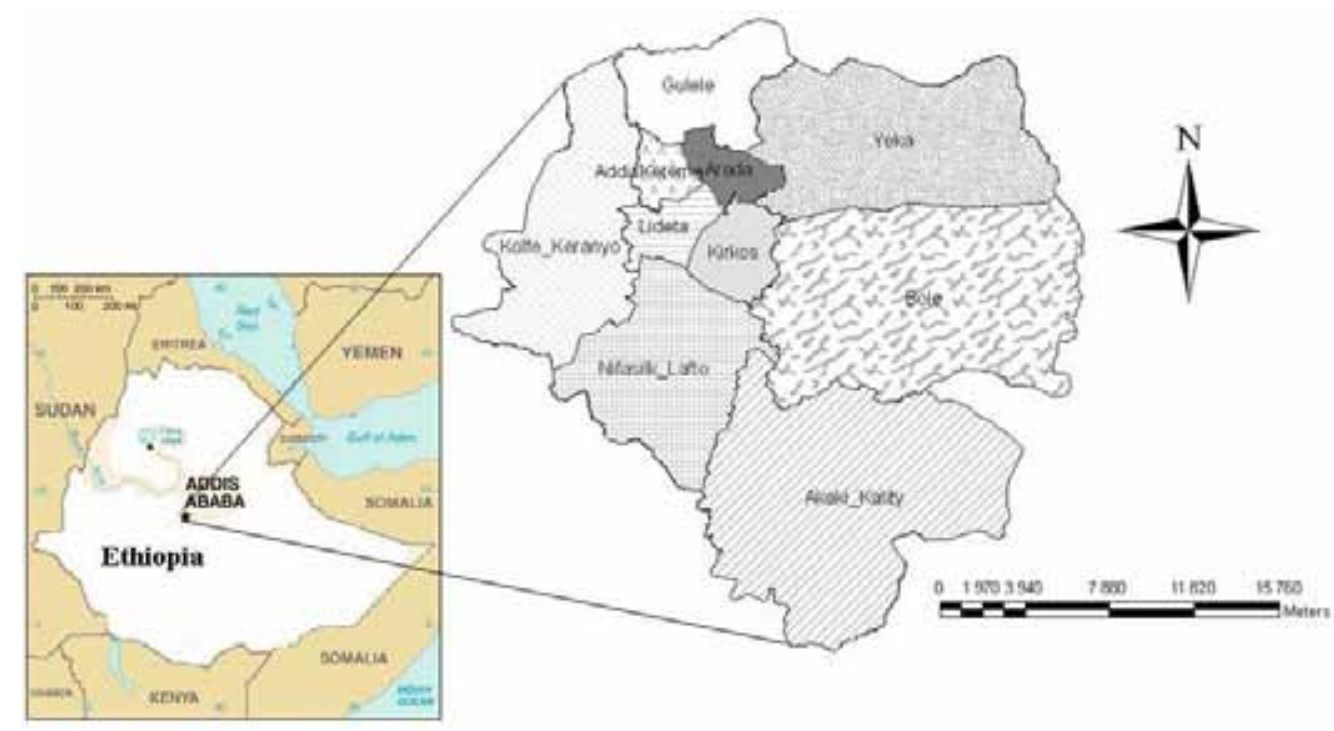

Figura 07 - Região Metropolitana de Addis Abeba.

Fonte: Apresentação do C40 large Cities Climate Summit São Paulo Brazil: The Case of Addis Ababa 
Para minimizar essas condições precárias e recuperar os recursos naturais, o governo criou um Plano Diretor, determinando a transformação de 22.000 ha de terras em áreas verdes, o que significa $41 \%$ do total da área da cidade. Essas áreas verdes incluem: florestas, parques públicos de recreação, parques lineares ao longo de rios, e agricultura urbana. Foram criadas várias estufas, incentivando principalmente a substituição de espécies exóticas por espécies nativas, de crescimento rápido, para acelerar a arborização. O foco do planejamento da floresta urbana, incluiu um repovoamento vegetal, não só com árvores, mas também com arbustos e herbáceas, no intuito de melhorar a qualidade ambiental. A diversidade das árvores selecionadas em Addis Abeba chega a quinhentas espécies, superando as trezentas espécies nativas, existentes no próprio país. A espécie dominante era o eucalipto que está sendo substituído pela madeira vermelha africana (Haginea abyssinica).



Figura 08 - Viveiros de mudas para a arborização urbana em Addis Abeba.

Fonte: Apresentação do C40 large Cities Climate Summit São Paulo Brazil: The Case of Addis Abeba 
Estas metas em Addis Abeba foram de suma importância, tanto para a absorção de carbono e redução de poluição, como para criar uma oportunidade de emprego na criação de bosques, para consumo da madeira como recurso energético. Mais de 500 famílias dependem desse recurso para sua existência. A Etiópia foi reconhecida pela UNEP(Programa de Meio Ambiente da Nações meta Unidas) no seu esforço pelo plantio de árvores, 700 milhões em 2008.

Atualmente, a vegetação que cobre a cidade equivale a $16 \%$ desse número, sendo que a meta do Plano Diretor é $41 \%$.

\section{CONCLUSÕES E RECOMENDAÇÕES}

O encontro C40, ocorrido em São Paulo no inicio do mês de junho, chamou-nos a atenção para o fato de que as mudanças climáticas estão sendo notadas em vários locais do mundo, causadas principalmente por atividades humanas como: a destruição de grandes áreas florestadas, na queima de combustíveis e na expansão sem limites das áreas urbanizadas. Os impactos previstos são amplos, portanto tem-se que unir esforços na criação de políticas inovadoras de mitigação e enfrentamento desses desafios, onde as cidades têm um papel de destaque.

Notou-se que as apresentações do C40 apresentaram políticas e ações semelhantes, centradas em parâmetros fundamentalmente quantitativos, no tocante ao aumento de áreas verdes e plantio massivo de árvores nas cidades, porém, em todos os casos, faltou o conceito de planejamento ambiental urbano e regional atrelado a conceitos ecossistêmicos e de infraestrutura verde, o que poderia ter trazido ao encontro a ênfase em parâmetros qualitativos, que pudessem gerar mais discussão, no sentido de geração de idéias para melhor condução, tanto das políticas quanto das ações de implementação do verde nas áreas urbanas.

Observe-se o caso do município São Paulo, que concentra 10 milhões de habitantes, com densidade de 5.500 habitantes por $\mathrm{km}^{2}$, o equivalente a $56 \%$ da população da Região Metropolitana, que teve seu suporte físico exposto a dilapidações irreversíveis, como: a ocupação inadequada de áreas de potencial paisagístico relevante e áreas de fundo de vale; a sistemática impermeabilização do solo pela urbanização contínua e deficiência de áreas verdes. O conjunto desses impactos propiciou enchentes de enormes proporções e o surgimento das "ilhas de calor". Nos últimos anos a Prefeitura do 
Município de São Paulo, através da Secretaria do Verde e Meio Ambiente, vem fazendo inúmeros esforços no sentido de ampliação do verde na Cidade ${ }^{6}$, haja vista a criação de novas áreas verdes e a implementação de parques lineares em fundos de vale, em consonância com o Plano Diretor Estratégico de 2002, que previu uma estruturação urbana através de rios e córregos ${ }^{7}$. Porém diante da dimensão de sua área urbana, que se pode chamar aqui de "infraestrutura cinza", as ações verdes tornam-se insuficientes.

Para minimizar as quase 16 milhões de toneladas de $\mathrm{CO}_{2}$, que foram lançadas na atmosfera de São Paulo em 2003, o poder público, por meio da Secretaria Municipal do Meio Ambiente, trouxe para São Paulo o conceito de cidade compacta, enfatizando a ocupação dos vazios urbanos centrais, minimizando a expansão dos assentamentos em áreas periféricas. A Prefeitura criou em 2005 o Programa de Reflorestamento e entre 2006 e 2009 foram plantadas mais de 600.000 novas árvores na cidade. Paralelamente a esse programa de reflorestamento, o Plano Diretor Estratégico introduziu duas "frentes de Ação" o "Programa 100 Parques para São Paulo", lançado em janeiro de 2008, o qual levantou e reservou áreas para serem transformadas em parques em diversas regiões da cidade associado ao Programa de Recuperação Ambiental de cursos d'água e fundos de vale, com o objetivo de considerar a rede hídrica como elemento estruturador da urbanização. Os Parques Lineares, que acompanham os fundos de vale, vieram a constituir o principal eixo de ação desse programa, no intuito de resgatar a lógica ambiental da bacia hidrográfica. Esses Parques Lineares são, portanto, uma nova diretriz infra-estrutural, que passam a definir faixas de utilidade pública ao longo dos cursos d'água com o objetivo de implantação de uma infra-estrutura verde de recuperação ambiental e lazer, é o inicio de uma estruturação de infraestrutura verde. Temos um exemplo concreto e muito bem sucedido desta ação na descanalização de um dos córregos formadores do ribeirão do Ipiranga, dentro do Jardim Botânico de São Paulo, conforme mostra a figura abaixo. Neste caso, havia um passeio pavimentado que constituía o eixo de entrada daquela área verde. Por baixo do enorme piso de mosaico português que cobria o antigo eixo de acesso, corria o córrego tubulado, que carregava consigo as águas das nascentes preservadas do ribeirão histórico, hoje descanalizado e com margens revegetadas, e contando com um passeio em deck de madeira que atrai os visitantes à observação do curso d'água, que ora corre a céu aberto, e a flora e fauna locais.

\footnotetext{
${ }^{6}$ Vale lembrar que em 2005 a cidade possuía somente 34 parques municipais -15 mil metros quadrados de area protegida; em 2008 esse número aumentou para 48 parques -24 mil metros quadrados - e o objetivo atual é de alçancar 50 mil metros quadrados até 2012 - Sao Paulo and the Climate Change. Prefeitura Municipal de São Paulo, encontro: Climate Summit C40, junho de 2011.

7 “Programa 100 Parques para São Paulo", lançado em janeiro de 2008.
} 


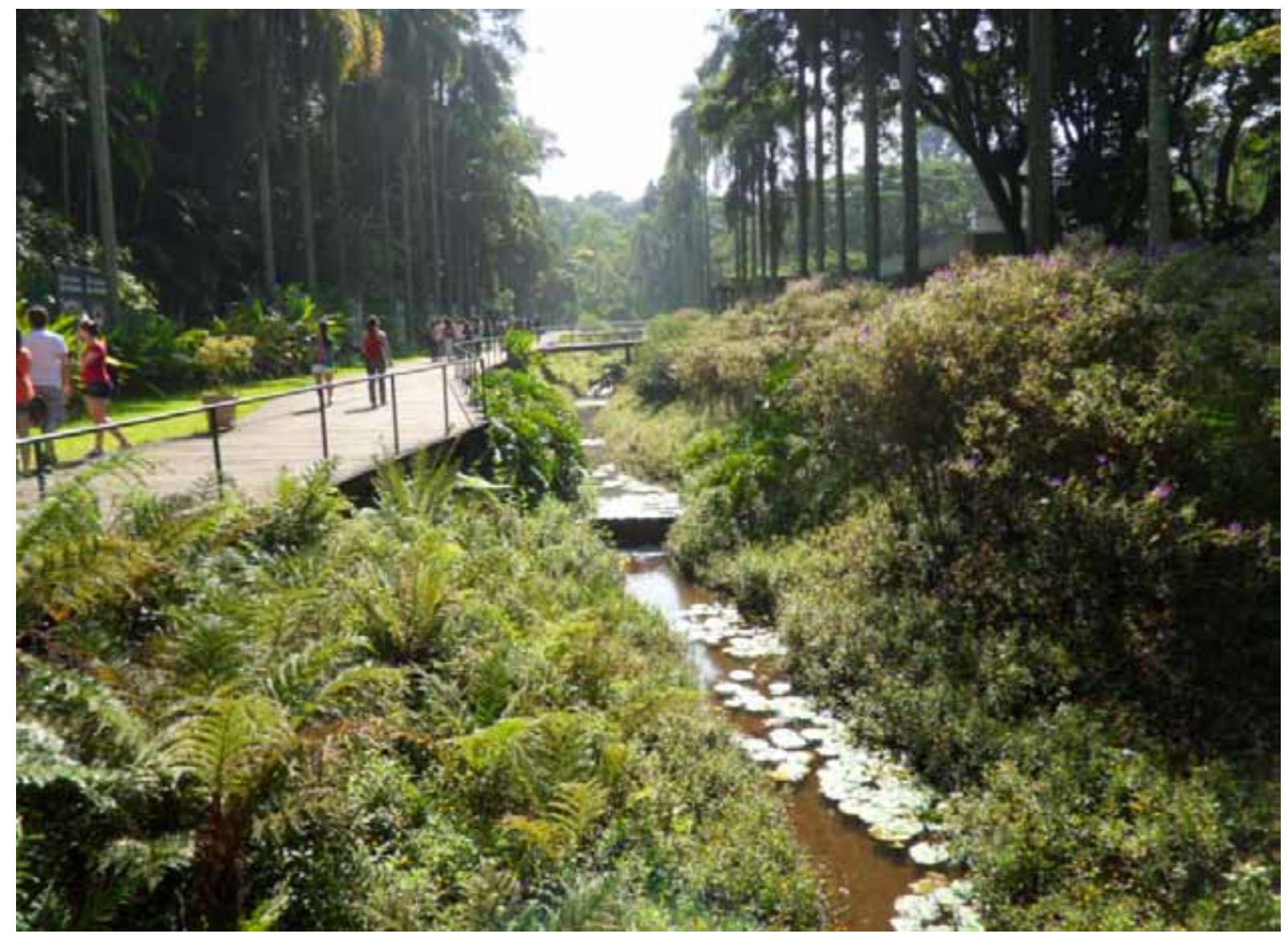

Figura 09 - Córrego descanalizado no Jardim Botânico de São Paulo.

Fonte: Arquivo de Maria de Assunção Ribeiro Franco.

Apesar da cidade de São Paulo apresentar diversas áreas verdes, desde florestas urbanas a parques, praças, jardins e outras, a maior parte delas estão desconectadas umas das outras, e sem interação amigável com a trama urbana. Portanto é recomendável a adoção de uma nova estratégia de Planejamento Ambiental, na qual o espaço da cidade deve ser pensado como um ecossistema urbano, articulado ao seu próprio ecossistema natural, permitindo a sobrevivência da vida selvagem, nas escalas urbana e regional, com a implementação do conceito de Infraestrutura Verde, que considere o verde urbano não isoladamente, mas em tipologias de espaços vedes interligados entre si, e com a malha urbana, num sistema em rede. Somente assim pode-se imaginar a cidade de São Paulo como uma cidade resiliente às mudanças climáticas. ${ }^{8}$

Assim, tendo em vista as reflexões sobre as contribuições do encontro C40 e as conclusões dispostas acima, podem ser feitas as seguintes recomendações:

\footnotetext{
${ }^{8}$ Newman, Beatley and Boyer, Resilient Cities, 2009.
} 
1. Criação de uma Infraestrutura Verde para a Cidade de São Paulo, por meio de um Planejamento Ambiental, em escala urbana e regional, que possa embasar uma revisão do Plano Diretor.

2. Criação de conectividade entre as áreas verdes urbanas existentes e futuras - a Infraestrutura Verde implica em conectividade entre as partes - entre as áreas núcleo e sítios por meio de corredores biológicos ou corredores verdes - em sintonia com os contextos culturais de bairro e locais.

3. A infraestrutura verde precisa ser planejada juntamente com as demais infraestruturas de planejamento urbano, servindo de guia para a conservação e o desenvolvimento.

4. A infraestrutura verde requer fazer conexões entre as comunidades e seus entornos - calçadas, travessias, passarelas, que propiciem a continuidade amigável entre os espaços urbanos. Portanto ela promove o entrelaçamento entre sua "rede verde" e as "redes de transporte limpo" com prevalência do pedestre, da ciclovia e do transporte público não poluente.

5. A infraestrutura verde deve promover a descanalização e recuperação de córregos e rios e suas várzeas.

6. A infraestrutura verde requer compromisso de longo prazo e o envolvimento entre os agentes sociais: o governo, a iniciativa privada, as organizações não governamentais e das pessoas em geral.

7. A infraestrutura verde necessita de uma lei específica que dê embasamento, tanto em sua fase de planejamento, projeto e execução, quanto em seu monitoramento e gestão continuados, que a valorize e que legitime sua proteção, conservação e seu usufruto pelos cidadãos.

8. A infraestrutura verde deve ser criada para a cidade de São Paulo tendo em vista o balanço hídrico e climático em escala regional levando em conta: o seqüestro de carbono, a promoção da biodiversidade no âmbito urbano, a prevenção de enchentes e a mitigação de suas "ilhas de calor", na tentativa de colaborar globalmente para a redução do "efeito estufa" e o "aquecimento global". 
9. A criação ou adaptação de órgão governamental que gerencie e monitore a Infraestrutura Verde da Cidade de São Paulo.

10. A criação da infraestrutura verde para a Cidade de São Paulo deve, acima de tudo, revelar que está embasada numa conscientização ambiental crescente, por parte do governo, dos empreendedores, dos especialistas e de todos os seus cidadãos, cujo foco principal é a proteção e conservação da vida dos homens e das espécies sob uma ética ecológica. 


\section{REFERÊNCIAS BIBLIOGRÁFICAS}

BENEDICT, Mark A.; McMAHON T. Green Infrastructure: Linking Landscapes and Communities. Washington, DC; Island Press, 2009.

DRAMSTAD, Wenche E.; OLSON, James D.; FORMAN, Richard T.T. Landscape Ecology Principles in Landscape Architecture and Land-Use Planning. Harvard University Graduate School of Design: Island Press and ASLA, MA, U.S.A., 1996.

FRANCO, Maria de Assunção Ribeiro. Planejamento Ambiental para a Cidade Sustentável. São Paulo, Annablume/EDIFURB, 2ªEd., 2001.

Desenho Ambiental - Introdução à Arquitetura da Paisagem com o Paradigma Ecológico. 2a . Edição, São Paulo, Annablume: Fapesp, 2008.

Infraestrutura Verde em São Paulo: o Caso do Corredor Verde Ibirapuera-Villa Lobos. São Paulo, FAU-USP, in Revista LABVERDE n01 p.134154; outubro de 2010.

LITTLE, Charles E. Greenways for America. Baltimore,EUA. John Hopkins University Press, 1995.

NEWMAN, Peter; BEATLEY,Timothy; BOYER, Heather. Resilient Cities: Responding to Peak Oil and Climate Change. Washington, DC, Island Press, 2009.

SÃO PAULO (Município), Secretaria Municipal de Planejamento Urbano /Secretaria Municipal do Verde e Meio Ambiente. Atlas Ambiental do Município de São Paulo. São Paulo, 2002.

SÃO PAULO (Município), Secretaria do Vede e de Meio Ambiente/Departamento de Parques e Áreas Verdes. Guia dos Parques Municipais de São Paulo, São Paulo, 2012.

THE WORLD BANK. Climate Change, Disaster Risk, and the Urban Poor. Washington DC, The International Bank for Reconstruction and Development/ The World Bank, 2012.

WATSON, Donald; ADAMS,Michele. Design for Flooding: Architecture, Landscape, and Urban Design for Resilience to Climate Change. New Jersey, Wiley \& Sons, 2011. 